\title{
Treatment outcomes of patients with multidrug and extensively drug-resistant tuberculosis in Zhejiang, China
}

\author{
Ming-Wu Zhang ${ }^{1}$, Lin Zhou ${ }^{1}$, Yu Zhang ${ }^{1}$, Bin Chen ${ }^{1}$, Ying Peng ${ }^{1}$, Fei Wang ${ }^{1}$, Zheng-Wei Liu', \\ Xiao-Meng Wang ${ }^{2^{*}}$ and Song-Hua Chen ${ }^{1 *}$
}

\begin{abstract}
Background: The aim of this study was to assess the treatment outcomes of multidrug and extensively drug-resistant tuberculosis (M/XDR-TB) in Zhejiang, China and to evaluate possible risk factors associated with poor outcomes of M/XDR-TB.

Methods: Two-hundred-and-sixty-two patients having M/XDR-TB who received the diagnosis and treatment at nine referral hospitals from 1 January 2016 to 31 December 2016 in Zhejiang, China were included. All patients received second-line regimens recommended by WHO under the DOTS-Plus strategy.

Results: Among the 262 patients, the treatment success rate was 55.34\% $(n=145)$ with 53.44\% $(n=140)$ cured and 1.91\% ( $n=5)$ who completed treatment, 62 (23.66\%) failed, 27 (10.31\%) died, 16 (6.11\%) defaulted and 12 (4.58\%) transferred out. Forty (64.52\%) of the $62 \mathrm{M} /$ XDR-TB patients who failed treatment were due to adverse effects in the first 10 months of treatment. Eighteen patients (6.37\%) had XDR-TB. Treatment failure was significantly higher among patients with XDR-TB at 50\% than that among patients with non-XDR-TB at $21.72 \%(P=0.006)$. Failure outcomes were associated with a baseline weight less than $50 \mathrm{~kg}(\mathrm{OR}, 8.668 ; 95 \% \mathrm{Cl} 1.679-44.756 ; P=0.010)$, age older than 60 years $(\mathrm{OR}, 9.053 ; 95 \% \mathrm{Cl} 1.606-51.027 ; P=0.013)$, hemoptysis $(\mathrm{OR}, 8.928 ; 95 \% \mathrm{Cl} 1.048-76.923 ; P=0.045)$, presence of cavitary diseases $(\mathrm{OR}, 10.204 ; 95 \% \mathrm{Cl} 2.032-52.631 ; P=0.005)$, or treatment irregularity $(\mathrm{OR}, 47.619 ; 95 \% \mathrm{Cl} 5.025-500$; $P=0.001)$.

Conclusion: Treatment outcomes for M/XDR-TB under the DOTS-Plus strategy in Zhejiang, China were favorable but still not ideal. Low body weight (<50 kg), old age (> 60 years), severe symptoms of TB including cavitary disease, hemoptysis and irregular treatment were independent prognostic factors for failure outcomes in patients with M/XDR-TB.
\end{abstract}

Keywords: Prognostic factors, M/XDR-TB treatment, Treatment failure, Smear-negative, Adverse effects

\section{Introduction}

Drug-resistant tuberculosis (TB) remains a growing threat to public health and there were an estimated 1.2 million TB deaths among human immunodeficiency virus (HIV) -negative people and an additional 208,000

\footnotetext{
*Correspondence: xmwang@cdc.zj.cn; shchen@cdc.zj.cn

${ }^{1}$ Zhejiang Provincial Center for Disease Prevention and Control, Hangzhou, Zhejiang, China

${ }^{2}$ Zhejiang Public Health Research Institute, Zhejiang, China
}

deaths among HIV-positive people in 2019 [1]. About half a million people developed rifampicin-resistant TB (RR-TB) worldwide in 2019 [2], of which 78\% had multidrug-resistant TB (MDR-TB) [3]. A global total of 206030 people with MDR/RR-TB were detected and almost $50 \%$ of the MDR-TB cases worldwide are estimated to occur in China and India [1]. Extensively drug-resistant tuberculosis (XDR-TB) is defined as MDR-TB with resistance to fluoroquinolone and at least one second-line injectable

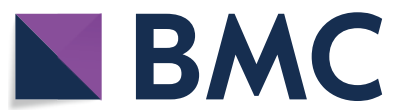

(c) The Author(s) 2021. This article is licensed under a Creative Commons Attribution 4.0 International License, which permits use, sharing, adaptation, distribution and reproduction in any medium or format, as long as you give appropriate credit to the original author(s) and the source, provide a link to the Creative Commons licence, and indicate if changes were made. The images or other third party material in this article are included in the article's Creative Commons licence, unless indicated otherwise in a credit line to the material. If material is not included in the article's Creative Commons licence and your intended use is not permitted by statutory regulation or exceeds the permitted use, you will need to obtain permission directly from the copyright holder. To view a copy of this licence, visit http://creativeco mmons.org/licenses/by/4.0/. The Creative Commons Public Domain Dedication waiver (http://creativecommons.org/publicdomain/ zero/1.0/) applies to the data made available in this article, unless otherwise stated in a credit line to the data. 
agent (i.e. amikacin, kanamycin, and/or capreomycin). XDR-TB has been reported from more than 58 countries and is estimated to occur in up to $10 \%$ of MDR-TB patients [3].

A five-year study revealed that, of 9544 MTB isolates, there were $3376(35.4 \%), 842(8.8 \%)$ and $61(0.64 \%)$ isolates identified as MDR-TB, XDR-TB and XDR-TB-Plus, respectively. The proportion of XDR-TB showed significant increase from $6.3 \%$ in 2011 to $9.1 \%$ in 2015[4].In Zhejiang province China, MDR-TB showed a decreasing trend, while resistance to any first-line drugs showed an increasing trend, and 3.21\%) and $21.28 \%$ MDR-TB cases were registered as new and previously treated cases, respectively. [5]. The prevalence of M/XDR-TB in Zhejiang Province underscores the continued need for effective treatment programs for drug-resistant TB.

This study aimed to investigate the outcomes of $\mathrm{M} /$ XDR-TB patients who were previously treated at provincial TB referral hospitals using the "DOTS-Plus" (a complementary DOTS-based strategy with provisions for treating multidrug-resistant tuberculosis) strategy, and to identify possible risk factors associated with poor treatment outcomes.

\section{Methods}

\section{Study area, participants and procedures}

The study area consisted of seven cities (Hangzhou, Huzhou, Shaoxing, Lishui, Quzhou, Jiaxing, and Wenzhou) including 39 counties with an urban area of about 19.2 million people in Zhejiang Province, China.

A total of 262 patients with culture-confirmed M/XDRTB who accepted treatment at the 9 referral hospitals from 1 Jan 2016 to 31 Dec 2016 including 18 XDR-TB patients were included in this study.

The definitions of MDR-TB and XDR-TB as defined by the WHO were used in this study. Patients diagnosed with M/XDR-TB based on the drug susceptibility test (DST) results received a standardized or individual treatment regimen (WHO) [6].

Standard definitions for MDR-TB treatment outcome as defined by the suggested criteria of J.E. Farley, M. Ram et al. were used in this project [7]. A patient was considered successfully treated if consistently culture-negative for the final 12 months of treatment with completed treatment which is defined as "cured" or if unknown for bacteriological results but does not meet the definition for cure which is defined as "treatment completed". An MDR-TB patient treatment interrupted for 2 or more consecutive months for any reason was defined as treatment default, while patient transferred to another unit with unknown treatment outcome was classified as "transfer out". "Failure" is regarded as $2-5$ positive cultures or 1 of any 3 positive cultures during the final 12 month of treatment.

\section{Data collection}

The treatment record of each patient was collected, e.g. information about symptoms of TB, baseline weight, and other characteristics (Table1). Results from the microbiology laboratory performed at the time of diagnosis of M/XDR-TB were reviewed and analyzed. All smear microscopy and culture on Lowenstein-Jensen media were positive. For all cases, isolates were sent for DST using the procedures of the provincial reference laboratories. All patients with M/XDR-TB isolates obtained prior to starting DOTS-Plus were sent to DST when the isolates were resistant to INH at $1 \mathrm{ug} / \mathrm{ml}$ and RMP at $40 \mathrm{ug} /$ $\mathrm{ml}$. In addition, these isolates sent to the laboratory for DST were tested for (resistance concentration): ethambutol (E), $2 \mathrm{ug} / \mathrm{ml}$; kanamycin $(\mathrm{Km}), 30 \mathrm{ug} / \mathrm{ml}$; streptomycin (S), $4 \mathrm{ug} / \mathrm{ml}$; and ofloxacin (Ofx), $2 \mathrm{ug} / \mathrm{ml}$.

\section{Treatment of patients with M/XDR-TB}

All cases were in residence in an area with DOTS-Plus implementation approved by the Green Light Committee (GLC) according to the Guidelines for the Programmatic Management of Drug-Resistant Tuberculosis [8]. Two-hundred-and-thirty-five (89.69\%) M/XDR-TB patients were treated under a standard regimen using the treatment protocol of $\mathrm{M} / \mathrm{XDR}-\mathrm{TB}$ and treatments of 27 (10.31\%) were individualized by each referral hospital on the basis of DST results and adverse reactions. An injectable agent (including aminoglycoside or capreomycin) was used for a minimum of 6 months and at least 4 months past culture conversion. After the initial intensive treatment, the whole duration was 24 months.

\section{Statistical analysis}

The data were checked for completeness and consistency. Crude odds ratios (OR) and 95\% confidence intervals (CI) were calculated using a stepwise logistic regression analysis with SPSS version 17.0 (SPSS, Inc., Chicago, IL, USA). The $\chi^{2}$ or the Fisher's exact test was used to determine the significant differences in frequencies of values in various groups where $P<0.05$ was considered significant.

\section{Results}

\section{Patients' characteristics}

In this study, 262 cases of M/XDR-TB were recruited for treatment, with 18 (6.87\%) having XDR-TB. The median age of the patients with XDR-TB and Non-XDR-TB were $52.83 \pm 14.95$ years (range $29-77$ ) and $46.07 \pm 16.17$ years (range 10-81), respectively. The majority of the patients $(73.28 \%, n=192)$ were male. The baseline characteristics of tuberculosis patients are shown in Table 1. 
Table 1 Characteristic of 262 patients with M/XDR-TB enrolled in the DOTS-Plus program in Zhejiang, China between 1 January and 31 December 2016

\begin{tabular}{|c|c|c|c|c|c|}
\hline Characteristic & $\begin{array}{l}\text { Total M/XDR-TB } \\
(n=262)\end{array}$ & $\begin{array}{l}\text { XDR-TB } \\
(n=18)\end{array}$ & $\begin{array}{l}\text { Non-XDR-TB } \\
(n=244)\end{array}$ & $x^{2}$ & $P$ \\
\hline \multicolumn{6}{|l|}{ Sex } \\
\hline Male & 192(73.28) & 13 & 179 & 0.011 & 0.916 \\
\hline Female & $70(26.72)$ & 5 & 65 & & \\
\hline \multicolumn{6}{|l|}{ Age } \\
\hline$<45$ & $128(48.85)$ & 5 & 123 & 4.776 & 0.092 \\
\hline $45-59$ & $69(26.34)$ & 5 & 64 & & \\
\hline$\geq 60$ & $65(24.81)$ & 8 & 57 & & \\
\hline \multicolumn{6}{|l|}{ Occupation $^{\mathrm{a}}$} \\
\hline Farmer & $147(56.11)$ & 10 & 137 & 2.054 & 0.152 \\
\hline Others & $115(43.89)$ & 8 & 107 & & \\
\hline \multicolumn{6}{|l|}{ Family register ${ }^{b}$} \\
\hline Resident & $124(47.33)$ & 8 & 116 & 0.064 & 0.800 \\
\hline Floating & $138(52.67)$ & 10 & 128 & & \\
\hline \multicolumn{6}{|l|}{ Previous TB treatment } \\
\hline No & $21(8.02)$ & 0 & 21 & 1.684 & 0.194 \\
\hline Yes & $241(91.98)$ & 18 & 223 & & \\
\hline \multicolumn{6}{|l|}{ TB symptoms } \\
\hline Hemoptysis & $181(69.08)$ & 13 & 168 & 0.089 & 0.765 \\
\hline Cavity & $127(48.47)$ & 13 & 114 & 6.752 & 0.009 \\
\hline Hospitalized & $66(25.19)$ & 2 & 64 & 2.033 & 0.154 \\
\hline \multicolumn{6}{|l|}{ Comorbidities } \\
\hline Impaired renal function & $82(31.30)$ & 6 & 76 & 3.795 & 0.164 \\
\hline Diabetes & $5(1.91)$ & 0 & 5 & 3.433 & 0.150 \\
\hline Liver disease & $2(0.76)$ & 0 & 2 & 3.620 & 0.150 \\
\hline
\end{tabular}

Data are No. (\%)

a Others including students and other occupations not investigated specifically

b Permanent local residents were classified as "resident", others as "Floating"

There was no significant difference between patients infected with MDR-TB and XDR-TB in terms of baseline weight, comorbidities, and laboratory findings. However, the presence of cavities at the time of diagnosis was more common in XDR-TB patients than those with Non-XDRTB $(72.22 \%$ vs $46.72 \%, P=0.009)$ (Table 1$)$.

The resistance patterns are shown in Fig. 1; all patients were resistant to isoniazid and rifampicin. Among the second-line drugs, resistance to streptomycin (160, $61.07 \%)$ and ethambutol $(107,40.84 \%)$ was common; while resistance to ofloxacin $(39,14.89 \%)$ and kanamycin $(19,7.25 \%)$ was rare. Overall, $33.6 \%$ of the strains from the patients were resistant to at least one secondline anti-TB drug (ethambutol, streptomycin or ofloxacin). Multidrug resistance patterns were predominantly resistant to $\mathrm{R} / \mathrm{H}, \mathrm{R} / \mathrm{H} / \mathrm{S} / \mathrm{E}$ and $\mathrm{R} / \mathrm{H} / \mathrm{S}$ at $27.86 \%, 24.81 \%$ and $24.05 \%$, respectively (Fig. 2). Resistance to 5 or more drugs accounted for $9.54 \%$ of the multidrug resistance.

\section{Outcomes of the treatment}

Among all patients, the treatment success rate was $55.34 \%(n=145)$ with $53.44 \%(n=140)$ cured and $1.91 \%$ $(n=5)$ treatment completed. Treatment failure occurred in 62 patients $(23.66 \%)$ and $27(10.31 \%)$ died during treatment. A further 16 (6.11\%) patients defaulted and $12(4.58 \%)$ patients transferred out to other cities with unknown treatment outcome (Table 2). Of 140 cured patients, 136 (97\%) converted to smear-negative in the first 6 months of treatment $\left(x^{2}=113.540, P<0.001\right)$. Sixteen deaths $(59.26 \%$ of the deaths) occurred in the first 6 months and 11 (40.74\%) additional deaths occurred during the remaining 18 months of the treatment program.

The median duration of treatment success was 730.60 days (95\% CI 717-731 days) for patients with XDR-TB and 730.65 days (95\% CI 730.48-730.80 days) for patients with Non-XDR-TB. 

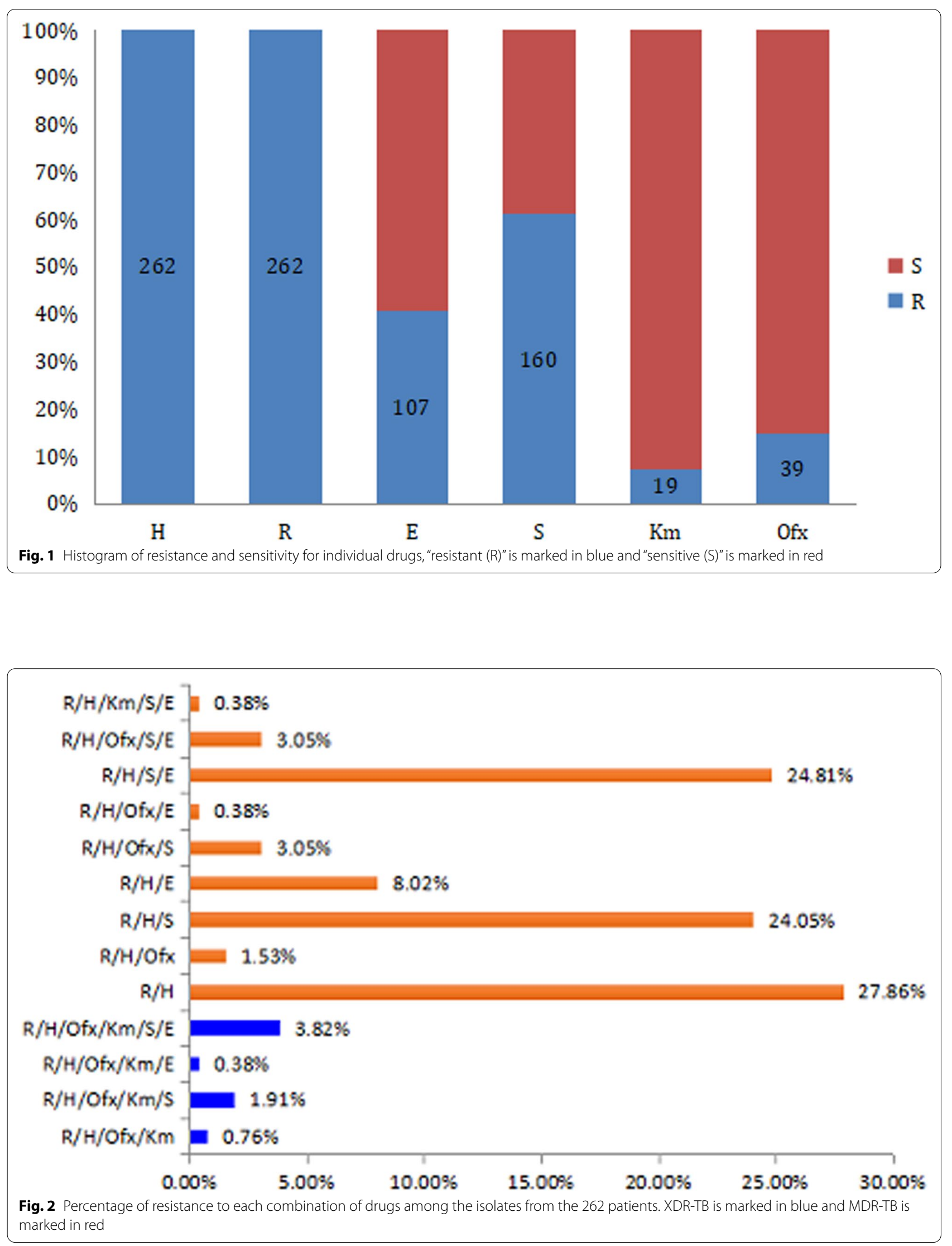
Table 2 Treatment outcomes and adverse reactions among patients with M/XDR-TB

\begin{tabular}{|c|c|c|c|c|c|}
\hline Treatment outcome & $\begin{array}{l}\text { Total MDR-TB } \\
(N=262), n(\%)\end{array}$ & $\begin{array}{l}\text { XDR-TB } \\
(N=18), n(\%)\end{array}$ & $\begin{array}{l}\text { Non-XDR-TB } \\
(N=244), n(\%)\end{array}$ & $x^{2}$ & $P$ \\
\hline Treatment success (Cure, TC) & 145(55.34) & 6(33.33) & 139(56.97) & 3.789 & 0.052 \\
\hline Cure & $140(53.44)$ & 6(33.33) & 134(54.92) & 2.331 & 0.126 \\
\hline Completed & $5(1.91)$ & $0(0.00)$ & $5(2.05)$ & 0.078 & 0.779 \\
\hline Failure & $62(23.66)$ & $9(50.00)$ & $53(21.72)$ & 7.420 & 0.006 \\
\hline Death & $27(10.31)$ & $2(11.11)$ & $25(10.25)$ & 0.081 & 0.775 \\
\hline Default & $16(6.11)$ & $0(0.00)$ & $16(6.56)$ & 0.373 & 0.541 \\
\hline Transfer out & $12(4.58)$ & $1(5.56)$ & $11(4.51)$ & 0.143 & 0.704 \\
\hline Adverse drug reactions & $122(46.55)$ & 7(38.89) & $115(47.13)$ & 0.458 & 0.499 \\
\hline Gl upset ${ }^{a}$ & $98(37.40)$ & $5(27.78)$ & $93(38.11)$ & 2.313 & 0.315 \\
\hline Hepatotoxicity & 36(13.74) & $1(5.56)$ & $35(14.34)$ & 5.522 & 0.063 \\
\hline Allergic reaction & $17(6.49)$ & $0(0.00)$ & $17(6.97)$ & 6.281 & 0.043 \\
\hline Neurologic abnormalities & $5(1.91)$ & $0(0.00)$ & $5(2.05)$ & 5.434 & 0.066 \\
\hline Mental disorder & $2(0.76)$ & $0(0.00)$ & $2(0.82)$ & 5.296 & 0.071 \\
\hline Hematologic abnormalities & $2(0.76)$ & $0(0.00)$ & $2(0.82)$ & 5.296 & 0.071 \\
\hline Electrolyte disturbances & $3(1.15)$ & $0(0.00)$ & $3(1.23)$ & 5.429 & 0.068 \\
\hline Renal toxicity & $5(1.91)$ & $0(0.00)$ & $5(2.05)$ & 5.434 & 0.066 \\
\hline Arthralgia or Courbature & $25(9.54)$ & $2(11.11)$ & 23(9.43) & 3.975 & 0.137 \\
\hline Hypothyroidism & 10(3.82) & $1(5.56)$ & $9(3.69)$ & 5.049 & 0.080 \\
\hline
\end{tabular}

a Gl gastrointestinal

\section{Risk factors for treatment failure}

The difference in treatment outcome was not statistically significant for gender, occupation, family register or other characteristics (Table 3).

Further, a total of $107(40.84 \%)$ of the patients were resistant to ethambutol, $160(61.07 \%)$ resistant to streptomycin, 19 (7.25\%) resistant to kanamycin and 39 (14.89\%) resistant to ofloxacin based on the DST results. Likewise, treatment outcomes did not indicate any significant difference between these drug-resistant patients (Table 3).

The treatment failure rate in XDR-TB group was $50 \%$ $(n=9)$, significantly higher than the Non-XDR-TB group (21.72\%, $n=53, P=0.006$; Table 2). Failure outcomes were more likely to occur if there was resistance to 6 or more drugs $(\mathrm{R} / \mathrm{H} / \mathrm{Of} \mathrm{x} / \mathrm{Km} / \mathrm{S} / \mathrm{E})(P=0.014$; Table 2$)$.

In this study, $27 \mathrm{M} / \mathrm{XDR}-\mathrm{TB}$ patients were treated with individualized regimens according to the DST results and other clinical symptoms. The overall success rate was much lower at $33.33 \%$ in comparison to $57.87 \%$ for those treated with standard regimen, partly due to that the death rate was much higher (29.63\% versus $8.09 \%)$. The failure rate was similar between the two treatment regimens (33.33\% versus $22.55 \%)$.

Further multivariate logistic regression analysis found that treatment failure was associated with baseline weight less than $50 \mathrm{~kg}$ (OR, 8.668; 95\% CI 1.679-44.756; $P=0.010$ ), older than 60 years (OR, 9.053; 95\% CI 1.606-51.027; $P=0.013$ ), hemoptysis or blood in sputum
(OR, 8.928; 95\% CI 1.048-76.923; $P=0.045)$, presence of cavitary disease (OR, 10.204; 95\% CI 2.032-52.631; $P=0.005)$, or treatment irregularity (OR, 47.619; 95\% CI 5.025-500; $P=0.001$ ) (Table 3).

Forty $(64.52 \%)$ of the $62 \mathrm{M} / \mathrm{XDR}-\mathrm{TB}$ patients failed in the treatment due to adverse effects in the first 10 months of treatment. The median duration from the onset of treatment to fail was 92.5 days (95\% CI 123.68230.98 days). Twenty-two patients in the failure group had also been affected by other factors, such as irregular treatment, poor health condition and other reasons.

Twenty-seven patients (10.31\%) died during treatment. Death during treatment was significantly associated with resistance to Ethambutol $(P=0.045)$ or treatment irregularity $(P=0.004)$ (Additional file 1 : Table $S 1)$.

\section{Adverse effects}

One-hundred-and-twenty two patients (46.55\%) experienced major clinically significant adverse effects caused by treatment, of which the most common was gastrointestinal (GI) upset $(98,37.40 \%)$, followed by hepatotoxicity $(36,13.74 \%)$, arthralgia or muscle pain $(25,9.54 \%)$ and allergic reaction $(17,6.49 \%)$. There were significantly more cases of allergic reaction in the Non-XDR-TB group $(P=0.043)$. In our study, adverse drug effects occurred frequently in first 3 months of the treatment. The median duration of adverse effects was 92.50 days. 
Table 3 Factors associated with Treatment failure of 262 patients with M/XDR-TB

\begin{tabular}{|c|c|c|c|c|c|c|c|c|c|c|}
\hline \multirow[t]{2}{*}{ Chracteristic } & \multicolumn{2}{|c|}{$\begin{array}{l}\text { Treatment } \\
\text { success }^{c}\end{array}$} & \multicolumn{2}{|c|}{$\begin{array}{l}\text { Treatment } \\
\text { failure }\end{array}$} & \multicolumn{2}{|l|}{ Total } & \multicolumn{2}{|l|}{ Univariate analysis } & \multicolumn{2}{|l|}{ Multivariate analysis } \\
\hline & \multicolumn{2}{|c|}{ Cure, TC n(\%) } & \multicolumn{2}{|c|}{ Failure $(n, \%)$} & \multicolumn{2}{|c|}{$N(\%)$} & OR $(95 \% \mathrm{Cl})^{d}$ & $P$ & OR (95\% Cl) & $P$ \\
\hline \multicolumn{11}{|l|}{ Sex } \\
\hline Male & 105 & 54.69 & 42 & 21.88 & 192 & 73.28 & $1.25(0.656-2.383)$ & 0.498 & $0.66(0.109-4.011)$ & 0.652 \\
\hline Female & 40 & 57.14 & 20 & 28.57 & 70 & 26.72 & 1 & & 1 & \\
\hline \multicolumn{11}{|l|}{ Age } \\
\hline$<60$ year & 124 & 62.94 & 35 & 17.77 & 197 & 75.19 & $4.555(2.302-9.015)$ & 0.000 & $9.053(1.606-51.027)$ & 0.013 \\
\hline$\geq 60$ year & 21 & 32.31 & 27 & 41.54 & 65 & 24.81 & 1 & & 1 & \\
\hline \multicolumn{11}{|l|}{ Occupation ${ }^{\mathrm{a}}$} \\
\hline Farmer & 108 & 54.82 & 47 & 23.86 & 197 & 75.19 & $0.932(0.467-1.859)$ & 0.841 & $1.343(0.262-6.898)$ & 0.724 \\
\hline Others & 37 & 56.92 & 15 & 23.08 & 65 & 24.81 & 1 & & 1 & \\
\hline \multicolumn{11}{|l|}{ Family register $^{\mathrm{b}}$} \\
\hline Resident & 62 & 50 & 38 & 30.65 & 124 & 47.33 & $0.472(0.257-0.866)$ & 0.015 & $5.502(0.778-38.935)$ & 0.088 \\
\hline Floating & 83 & 60.14 & 24 & 17.39 & 138 & 52.67 & 1 & & 1 & \\
\hline \multicolumn{11}{|l|}{ Previous TB treatment } \\
\hline No & 14 & 66.67 & 4 & 19.05 & 21 & 8.02 & $1.55(0.489-4.911)$ & 0.457 & $2.033(0.113-36.662)$ & 0.631 \\
\hline Yes & 131 & 54.36 & 58 & 24.07 & 241 & 91.98 & 1 & & 1 & \\
\hline \multicolumn{11}{|l|}{ Weight } \\
\hline$<50 \mathrm{~kg}$ & 19 & 44.19 & 16 & 37.21 & 43 & 16.41 & $2.824(1.198-6.657)$ & 0.018 & $8.668(1.679-44.756)$ & 0.01 \\
\hline$>=50 \mathrm{~kg}$ & 57 & 64.04 & 17 & 19.1 & 89 & 33.97 & 1 & & 1 & \\
\hline \multicolumn{11}{|l|}{ TB symptoms } \\
\hline \multicolumn{11}{|l|}{ Hemoptysis } \\
\hline Yes & 105 & 58.01 & 38 & 20.99 & 181 & 69.08 & $0.603(0.322-1.129)$ & 0.114 & $8.928(1.048-76.923)$ & 0.045 \\
\hline No & 40 & 49.38 & 24 & 29.63 & 81 & 30.92 & 1 & & 1 & \\
\hline \multicolumn{11}{|l|}{ Cavitary } \\
\hline Yes & 42 & 33.07 & 42 & 33.07 & 127 & 48.47 & $5.154(2.71-9.803)$ & 0.000 & $10.204(2.032-52.631)$ & 0.005 \\
\hline No & 103 & 76.3 & 20 & 14.81 & 135 & 51.53 & 1 & & 1 & \\
\hline \multicolumn{11}{|l|}{ Treatment } \\
\hline Standard treatment & 136 & 57.87 & 53 & 22.55 & 235 & 89.69 & $2.566(0.966-6.816)$ & 0.059 & $0.447(0.027-7.449)$ & 0.575 \\
\hline Individualized treatment & 9 & 33.33 & 9 & 33.33 & 27 & 10.31 & 1 & & 1 & \\
\hline Hosipitalization & & & & & & & & & & \\
\hline No & 115 & 58.67 & 41 & 20.92 & 196 & 74.81 & $0.509(0.263-0.987)$ & 0.046 & $0.365(0.066-2.009)$ & 0.247 \\
\hline Yes & 30 & 45.45 & 21 & 31.82 & 66 & 25.19 & 1 & & 1 & \\
\hline Liver protection drugs & & & & & & & & & & \\
\hline Yes & 38 & 48.72 & 24 & 30.77 & 78 & 29.77 & $1.779(0.946-3.344)$ & 0.074 & $1.764(0.935-142.857)$ & 0.056 \\
\hline NO & 107 & 58.15 & 38 & 20.65 & 184 & 70.23 & 1 & & 1 & \\
\hline First-line oral anti-TB agents & & & & & & & & & & \\
\hline Ethambutol & & & & & & & & & & \\
\hline $\mathrm{R}$ & 58 & 54.21 & 25 & 23.36 & 107 & 40.84 & $0.987(0.538-1.81)$ & 0.965 & $1.721(0.37-8.009)$ & 0.489 \\
\hline $\mathrm{S}$ & 87 & 56.13 & 37 & 23.87 & 155 & 59.16 & 1 & & 1 & \\
\hline Injectable anti-TB agents & & & & & & & & & & \\
\hline Streptomycin & & & & & & & & & & \\
\hline $\mathrm{R}$ & 92 & 57.5 & 34 & 21.25 & 160 & 61.07 & $1.43(0.782-2.614)$ & 0.246 & $1.85(0.46-7.451)$ & 0.387 \\
\hline S & 53 & 51.96 & 28 & 27.45 & 102 & 38.93 & 1 & & 1 & \\
\hline Kanamycin & & & & & & & & & & \\
\hline $\mathrm{R}$ & 7 & 36.84 & 9 & 47.37 & 19 & 7.25 & $0.299(0.106-0.843)$ & 0.022 & $0.137(0.005-3.663)$ & 0.236 \\
\hline $\mathrm{S}$ & 138 & 56.79 & 53 & 21.81 & 243 & 92.75 & 1 & & 1 & \\
\hline Fluoroquinolones & & & & & & & & & & \\
\hline Ofloxacin & & & & & & & & & & \\
\hline
\end{tabular}


Table 3 (continued)

\begin{tabular}{|c|c|c|c|c|c|c|c|c|c|c|}
\hline \multirow{3}{*}{$\begin{array}{l}\text { Chracteristic } \\
\\
\mathrm{R}\end{array}$} & \multirow{2}{*}{\multicolumn{2}{|c|}{$\begin{array}{l}\begin{array}{l}\text { Treatment } \\
\text { success }^{c}\end{array} \\
\text { Cure, TC } n(\%)\end{array}$}} & \multirow{2}{*}{\multicolumn{2}{|c|}{$\begin{array}{l}\begin{array}{l}\text { Treatment } \\
\text { failure }\end{array} \\
\text { Failure }(n, \%)\end{array}$}} & \multirow{2}{*}{\multicolumn{2}{|c|}{$\begin{array}{l}\text { Total } \\
N(\%)\end{array}$}} & \multicolumn{2}{|l|}{ Univariate analysis } & \multicolumn{2}{|l|}{ Multivariate analysis } \\
\hline & & & & & & & \multirow{2}{*}{$\begin{array}{l}\text { OR }(95 \% \text { CI })^{d} \\
0.366(0.163-0.825)\end{array}$} & \multirow{2}{*}{$\begin{array}{l}P \\
0.015\end{array}$} & \multirow{2}{*}{$\begin{array}{l}\text { OR }(95 \% \text { Cl) } \\
0.793(0.101-6.209)\end{array}$} & \multirow{2}{*}{$\begin{array}{l}P \\
0.825\end{array}$} \\
\hline & 14 & 35.9 & 14 & 35.9 & 39 & 14.89 & & & & \\
\hline S & 131 & 58.74 & 48 & 21.52 & 223 & 85.11 & 1 & & 1 & \\
\hline \multicolumn{11}{|l|}{ Treatment regularity } \\
\hline No & 2 & 7.14 & 18 & 64.29 & 28 & 10.69 & $29.411(6.535-125)$ & 0.000 & $47.619(5.025-500)$ & 0.001 \\
\hline Yes & 143 & 61.11 & 44 & 18.8 & 234 & 89.31 & 1 & & 1 & \\
\hline \multicolumn{11}{|l|}{ Resistant pattern ${ }^{\mathrm{e}}$} \\
\hline $\mathrm{R} / \mathrm{H}$ & 38 & 52.05 & 21 & 28.77 & 73 & 27.86 & $0.693(0.364-1.319)$ & & & \\
\hline $\mathrm{R} / \mathrm{H} / \mathrm{E}$ & 13 & 61.90 & 4 & 19.05 & 21 & 8.02 & $1.428(0.447-4.566)$ & & & \\
\hline $\mathrm{R} / \mathrm{H} / \mathrm{S}$ & 42 & 66.67 & 11 & 17.46 & 63 & 24.05 & $1.891(0.899-3.978)$ & & & \\
\hline $\mathrm{R} / \mathrm{H} / \mathrm{S} / \mathrm{E}$ & 37 & 56.92 & 12 & 18.46 & 65 & 24.81 & $1.427(0.686-2.969)$ & & & \\
\hline $\mathrm{R} / \mathrm{H} / \mathrm{Ofx} / \mathrm{Km} / \mathrm{S} / \mathrm{E}$ & 3 & 30.00 & 6 & 60.00 & 10 & 3.82 & $0.131(0.026-0.666)$ & 0.014 & & \\
\hline
\end{tabular}

a others including student and other occupation not investigated in specific

b permanent local residence classified into "residence", otherwise "Floating"

c Treatment success including cured(Cure)and treatment completed(TC)

d $O R$ adjusted odd ratio, $\mathrm{Cl}$ confidence interval

e $H$ isoniazid, $R$ rifampicin, $E$ ethambutol, $S$ streptomycin, $K m$ kanamycin, $O f x$ ofloxacin. Analysis was done for patterns with at least 10 cases in total

\section{Discussion}

This study first analyzed the treatment outcomes of M/ XDR-TB in Zhejiang, China. The overall success rate was $55.34 \%$, with a success rate of $56.97 \%$ and $33.33 \%$ for patients with MDR-TB (excluding XDR-TB) and XDR-TB, respectively. The overall failure, defaulting and death rates were $23.66 \%, 6.11 \%$ and $10.31 \%$, respectively, with a combined rate of $50.8 \%$ contributing to the poor outcome. We identified several risk factors contributing to this poor treatment outcome.

The overall success rate detected in our present study is higher than other reports from China $[9,10]$. Liu Q et al. [9] reported a success rate of $50.7 \%$ for patients with MDR-TB and demonstrated that patients with pncA gene mutations, advanced age, and non-standard treatment had a significantly higher risk of poor treatment outcomes. Tang et al. [10] reported a success rate of only $40.95 \%$ in a cohort of 586 patients with $28.8 \%$ being XDR-TB patients. The higher proportion of XDRTB patients may have contributed to the lower success rate in that study. Reports from other countries showed a success rate ranging from $38.6 \%$ to $74.0 \%$ [11-14].

A study Carried out in Brazil reported the proportion of unfavourable outcomes was $41.9 \%$ among MDR-TB and $81.5 \%$ among XDR-TB, which were higher than those in our present study [15]. The study also revealed that bilateral disease, HIV-positive, and comorbidities were associated with death and XDR-TB patients had a 4.7-fold higher odds of an unfavourable outcome [15].
In our present study, of the 140 cured patients, 136 (97\%) of the patients converted to smear-negative in the first 6 months treatment course. However, a study conducted by Gao revealed that 24-week bedaquiline treatment combined with personalized anti-TB drug background regimens result in different initial sputum culture conversion rates, which were $84.6 \%$ for MDR-TB patients, $83.9 \%$ for pre-XDR-TB patients and $86.6 \%$ for XDR-TB patients [16]. The findings suggest that completing the initial treatment course of 6 months with injectable agents is critical for treatment success and also implies that any patient not cured during this first 6 months has a high chance of treatment failure and thus requires evaluation at the 6 months for treatment strategies.

In our study, 9 of the $27 \mathrm{M} / \mathrm{XDR}-\mathrm{TB}$ patients treated with individualized regimens according to the DST results and other clinical symptoms were successful (33.33\%) which was less favorable than those used standardized regimens with success rate of $57.87 \%$ (Table 3 ). However, there was no significant difference in the rate of treatment failure between standard and individualized treatments $(P=0.575)$. A study conducted in Korea reported that, delamanid-containing regimens resulted in a higher treatment success rate (81.6\%) [17]. Another multi-center study revealed that bedaquiline-containing regimens in the treatment of MDR- and XDR-TB achieved a success of $71.3 \%$ (62.4\% cured; $8.9 \%$ completed treatment).[18] Therefore, together with the introduction 
of new anti-TB agents, the individualized treatment regimens might be effective to improve MDR-TB treatment outcome.

The primary factors associated with poor treatment outcomes in our study were age ( $>60$ years), body weight $(\leq 50 \mathrm{~kg})$, with cavitary disease or hemoptysis symptoms, and treatment irregularity. In recent study conducted in China indicated that genetic mutation of MTB strains was responsible for some unfavorable outcome $[6,19]$. While another study performed in Brazil revealed that bilateral disease, HIV infection and comorbidities were associated with death [13]. These clinical signs are an indication of disease severity and are associated with diagnostic delays and prior long duration of treatment. Treatment irregularity as independent predictors of failure in M/XDR-TB patients was similarly reported by several studies $[20,21]$ underscoring the importance of patients receiving regular treatment. So the short-course treatment regimens according to drug-sensitivity test were conducted to provide more basis for MDR-TB treatment [22]. Even the study carried out among adolescent achieved treatment success rates of $88 \%$ and $83 \%$ with the 9-month regimen, and $90 \%$ and $75 \%$ with the 12 -month regimen in adults and children/adolescents [23].

Previous studies suggest an association between resistance to certain anti-TB drugs and poor treatment outcomes in MDR-TB patients [24]. Accumulated studies confirmed that anti-TB-drug resistance always derives from genetic mutations in MTB strains, and MDR-TB was caused by a series of genetic mutations in MTB strains $[25,26]$. Our study found no association of resistance to a single drug with treatment failure. However, resistance to 6 or more drugs was associated with treatment failure $(P=0.014)$. The results mean that the more mutations in the MTB strains the more risk of resistances to anti-TB drugs. The molecular mechanisms of MDR-TB incidence indicate that the resistance to anti-TB drugs might be unable to be reversed, so developing new effective anti-TB agents was necessary for further treatment.

Besides drug resistance, adverse effects associated with second-line drugs have been reported as obstacles in the management of M/XDR-TB [27]. In our study, the majority of the $62 \mathrm{M} / \mathrm{XDR}-\mathrm{TB}$ patients $(64.52 \%)$ failed treatment were due to adverse effects. This finding advocates that adequate management of adverse effects shall improve treatment outcomes substantially.

The defaulting rate in this study is $6.11 \%$. However, yet another study from China found that defaulting rate is $17 \%$ and a higher defaulting rate was also reported from Africa and India $[28,29]$. Defaulted M/XDR-TB patients could potentially continue to infect others and are a threat to public health, just as Chisompola et al. reported that primary drug resistance remained the predominant type of transmission [30]. Therefore, reducing defaulting rate is critical to reduce M/XDRTB spread.

Previous studies in Brazil and South Africa emphasize the roles of unemployment, socially disadvantaged patients, underweight, co-infection with HIV, alcohol and drug abuse and longer treatment duration in association with treatment default [31-34]. China has a massive floating population, and it was reported by $\mathrm{Li}$ et al. that the floating population and rural residents were considered high-risk groups for TB infection [35, 36]. This fact makes it especially challenging on treating M/XDR-TB case as risk of treatment default and transfer out is higher and far more difficult to manage in the floating population [35]. Further, treatment of M/XDR-TB is less effective, more toxic and more costly increases the risk of treatment default.

This study has several limitations. First, although a standard protocol and data collection format were used, data on patient's height and BMI are poorly documented. Second, the number of XDR-TB patients in this study was small. The findings cannot fully represent treatment outcomes of XDR-TB in China. Third, we only had monitoring data for deaths and default in the studied patients. There was no record for the cause of death nor detailed information on default to assess actual reasons. Fourth, this study did not use standardized definitions of adverse effects, their diagnosis or their degree of severity. Despite these limitations, we believe this study provides an important evaluation of treatment outcomes of $\mathrm{M}$ / XDR-TB, especially as the first evaluation report in Zhejiang, China of countrywide DOTS-Plus implementation program.

\section{Conclusion}

In conclusion, this study found that the treatment outcome for M/XDR-TB was favorable with a success rate of $55.34 \%$ but still not ideal since outcomes for $40.8 \%$ patients were poor, consisting of $23.66 \%$ failure, $10.31 \%$ deaths and $6.11 \%$ defaults. Thus substantial effort is required to improve treatment outcomes. Several risk factors identified may be mitigated through clinical management, such as timely diagnosis, regular treatment and controlling adverse effects, and improving social welfare, such as better nutrition and treatment affordability. Our data show that the first 6 months is critical in reducing treatment failure and deaths. This study has important implications for clinical management of M/XDR-TB.

\section{Abbreviations}

H: Isoniazid; R: Rifampicin; E: Ethambutol; S: Streptomycin; Km: Kanamycin; Ofx: Ofloxacin 


\section{Supplementary Information}

The online version contains supplementary material available at https://doi. org/10.1186/s40001-021-00502-0.

Additional file 1: Table S1. Risk factors for death among all M/XDR-TB patients registered for treatment in Zhejiang.

\section{Acknowledgements}

We appreciate the staff of the tuberculosis referral hospital in Zhejiang for their help in conducting the study.

\section{Authors' contributions}

$M Z$, FW and $Z L$ were responsible for data collection; $L Z, Y Z$ and $B C$ were responsible for data analysis; YP, XW and SC responsible for study design and implementation. All authors read and approved the final manuscript.

\section{Funding}

The study was supported by the quality of life and its influencing factors of MDR-TB patient research (scientific research fund of Zhejiang Provincial De-partment of Health (2015KYA056), Tuberculosis epidemic and intervention mode research (2013ZX10003004) and Study on Molecular Mechanism and Risk Prediction of Pulmonary Tuberculosis Based on microRNA Regulation (2020keyan512).

\section{Availability of data and materials}

The supporting data can be acquired via correspondence author.

\section{Declarations}

\section{Ethical approval and consent to participate}

This study was approved by the ethics committee of Zhejiang provincial center for disease control and prevention. A signed consent by each participant was asked to provide.

\section{Consent for publication}

All the authors were consent for publication.

\section{Competing interests}

No conflict of interest to declare.

Received: 7 January 2021 Accepted: 17 March 2021

Published online: 03 April 2021

\section{References}

1. WHO. Global tuberculosis report 2020. WHO/HTM/TB/202011 2020. (https://apps.who.int/iris/bitstream/handle/10665/336069/9789240013 131-eng.pdf)

2. Compendium of TB/COVID-19 studies. Geneva: World Health Organization; 2020 (https://www.who.int/ teams/global-tuberculosis-programme/ covid-19/compendium, accessed 29 July 2020).

3. Digital health for the End TB Strategy: an agenda for action (WHO/HTM/ TB/2015.21). Geneva: WHO; 2015 (https://www.who.int/tb/publications/ digitalhealth-TB-agenda/en/, accessed 29 July 2020).

4. Pang Y, Lu J, Huo F, Ma Y, Zhao L, Li Y, Liang Q, Chu N, Gao M, Huang H. Prevalence and treatment outcome of extensively drug-resistant tuberculosis plus additional drug resistance from the National Clinical Center for Tuberculosis in China: A five-year review. J Infect. 2017;75:433-40.

5. Wu B, Zhang L, Liu Z, He H, Pan A, Wang F, Zhang M, Chen B, Lu Z, Chen S, Wang X. Drug-resistant tuberculosis in Zhejiang Province, China: an updated analysis of time trends, 1999-2013. Glob Health Action. 2017;10:1293925.

6. Nunn AJ, Rusen ID, Van Deun A, Torrea G, Phillips PP, Chiang CY, Squire SB, Madan J, Meredith SK. Evaluation of a standardized treatment regimen of anti-tuberculosis drugs for patients with multi-drug-resistant tuberculosis (STREAM): study protocol for a randomized controlled trial. Trials. 2014;15:353.
7. Farley JE, Ram M, Pan W, Waldman S, Cassell GH, Chaisson RE, Weyer K, Lancaster J, Van der Walt M. Outcomes of multi-drug resistant tuberculosis (MDR-TB) among a cohort of South African patients with high HIV prevalence. PLOS ONE. 2011;6:e20436.

8. WHO. Companion Handbook to the WHO Guidelines for the Programmatic Management of Drug-Resistant Tuberculosis, Geneva, 2014.

9. Liu Q, Yang D, Qiu B, Martinez L, Ji Y, Song H, Li Z, Wang J. Drug resistance gene mutations and treatment outcomes in MDR-TB: A prospective study in Eastern China. PLoS Negl Trop Dis. 2021;15:e0009068.

10. Tang S, Tan S, Yao L, Li F, Li L, Guo X, Liu Y, Hao X, Li Y, Ding X, Zhang Z, Tong $L$, Huang J. Risk factors for poor treatment outcomes in patients with MDR-TB and XDR-TB in China: retrospective multi-center investigation. PLOS ONE. 2013;8:e82943.

11. Piparva KG, Jansari G, Singh AP. Evaluation of treatment outcome and adverse drug reaction of directly observed treatment (DOT) plus regimen in multidrug-resistant tuberculosis (MDR-TB) patients at district tuberculosis centre Rajkot. Perspect Clin Res. 2018;9:165-9.

12. Dela Al, Tank NKD, Singh AP, Piparva KG. Adverse drug reactions and treatment outcome analysis of DOTS-plus therapy of MDR-TB patients at district tuberculosis centre: A four year retrospective study, Lung India : official organ of Indian Chest Society. 34 (2017) 522-526.13.

13. Patel SV, Nimavat KB, Alpesh PB, Shukla LK, Shringarpure KS, Mehta KG, Joshi CC. Treatment outcome among cases of multidrug-resistant tuberculosis (MDR TB) in Western India: A prospective study. J Infect Public Health. 2016:9:478-84.

14. Hassane-Harouna S, Cherif GF, Ortuno-Gutierrez N, Cisse D, Camara LM, Diallo BD, Camara S, Bangoura AM, Lynen L, Decroo T. Better programmatic outcome with the shorter regimen for the treatment of multidrugresistant tuberculosis (MDR-TB) in Guinea: A retrospective cohort study. PLOS ONE. 2020;15:e0237355.

15. Bhering M, Duarte $R$, Kritski A. Predictive factors for unfavourable treatment in MDR-TB and XDR-TB patients in Rio de Janeiro State, Brazil, 2000-2016. PLOS ONE. 2019;14:e0218299.

16. Gao M, Gao J, Xie L, Wu G, Chen W, Chen Y, Pei Y, Li G, Liu Y, Shu W, Fan L, Wu Q, Du J, Chen X, Tang P, Xiong Y, Li M, Cai Q, Jin L, Mei Z, Pang Y, $L i L$, Early outcome and safety of bedaquiline-containing regimens for treatment of MDR- and XDR-TB in China: a multicentre study, Clinical microbiology and infection : the official publication of the European Society of Clinical Microbiology and Infectious Diseases, (2020).

17. Mok J, Kang H, Koh WJ, Jhun BW, Yim JJ, Kwak N, Lee T, Kang B, Jeon D. Final treatment outcomes of delamanid-containing regimens in patients with MDR-/XDR-TB in South Korea, The European respiratory journal, 54 (2019).

18. S.E. Borisov, K. Dheda, M. Enwerem, R. Romero Leyet, L. D’Ambrosio, R. Centis, G. Sotgiu, S. Tiberi, J.W. Alffenaar, A. Maryandyshev, E. Belilovski, S. Ganatra, A. Skrahina, O. Akkerman, A. Aleksa, R. Amale, J. Artsukevich, J. Bruchfeld, J.A. Caminero, I. Carpena Martinez, L. Codecasa, M. Dalcolmo, J. Denholm, P. Douglas, R. Duarte, A. Esmail, M. Fadul, A. Filippov, L. Davies Forsman, M. Gaga, J.A. Garcia-Fuertes, J.M. Garcia-Garcia, G. Gualano, J. Jonsson, H. Kunst, J.S. Lau, B. Lazaro Mastrapa, J.L. Teran Troya, S. Manga, K. Manika, P. Gonzalez Montaner, J. Mullerpattan, S. Oelofse, M. Ortelli, D.J. Palmero, F. Palmieri, A. Papalia, A. Papavasileiou, M.C. Payen, E. Pontali, C. Robalo Cordeiro, L. Saderi, T.D. Sadutshang, T. Sanukevich, V. Solodovnikova, A. Spanevello, S. Topgyal, F. Toscanini, A.R. Tramontana, Z.F. Udwadia, P. Viggiani, V. White, A. Zumla, G.B. Migliori, Effectiveness and safety of bedaquiline-containing regimens in the treatment of MDR- and XDR-TB: a multicentre study, The European respiratory journal, 49 (2017).

19. Farley JE, Ram M, Pan W, et al. Outcomes of multi-drug resistant tuberculosis (MDR-TB) among a cohort of South African patients with high HIV prevalence. PLoS ONE. 2011;6:e20436.

20. Jacobson KR, Tierney DB, Jeon CY, Mitnick CD, Murray MB. Treatment outcomes among patients with extensively drug-resistant tuberculosis: systematic review and meta-analysis. Clin Infect Dis. 2010;51:6-14.

21. Chen S, Huai $P$, Wang $X$, et al. Risk factors for multidrug resistance among previously treated patients with tuberculosis in eastern China: a casecontrol study. Int J Infect Dis. 2013;17:e1116-1120.

22. Lee M, Mok J, Kim DK, Shim TS, Koh WJ, Jeon D, Lee T, Lee SH, Kim JS, Park JS, Lee JY, Kim SY, Lee JH, Jo KW, Jhun BW, Kang YA, Ahn JH, Kim CK, Shin S, Song T, Shin SJ, Kim YR, Ahn H, Hahn S, Won HJ, Jang JY, Cho SN, Yim JJ. Delamanid, linezolid, levofloxacin, and pyrazinamide for the treatment of patients with fluoroquinolone-sensitive multidrug-resistant tuberculosis 
(Treatment Shortening of MDR-TB Using Existing and New Drugs, MDREND): study protocol for a phase II/III, multicenter, randomized, openlabel clinical trial. Trials. 2019;20:57.

23. Harouna SH, Ortuno-Gutierrez N, Souleymane MB, Kizito W, Morou S, Boukary I, Zolfo M, Benedetti G, Piubello A. Short-course treatment outcomes and adverse events in adults and children-adolescents with MDR-TB in Niger. Int J Tuberculosis Lung Dis . 2019;23:625-30.

24. Tabarsi P, Chitsaz E, Baghaei P, et al. Impact of extensively drug-resistant tuberculosis on treatment outcome of multidrug-resistant tuberculosis patients with standardized regimen: report from Iran. Microb Drug Resist. 2010;16:81-6

25. Matsui T, Pinhata JMW, Rabello M, Brandao AP, Ferrazoli L, Leao SC, VianaNiero C, Oliveira RS. Frequency of first and second-line drug resistanceassociated mutations among resistant Mycobacterium tuberculosis clinical isolates from Sao Paulo. Brazil, Memorias do Instituto Oswaldo Cruz. 2020;115:e200055

26. Sayadi M, Zare H, Jamedar SA, Hashemy SI, Meshkat Z, Soleimanpour S, Hoffner S, Ghazvini K. Genotypic and phenotypic characterization of Mycobacterium tuberculosis resistance against fluoroquinolones in the northeast of Iran. BMC Infect Dis. 2020:20:390.

27. Van der Walt M, Lancaster J, Odendaal R, Davis JG, Shean K, Farley J. Serious treatment related adverse drug reactions amongst anti-retroviral naive MDR-TB patients. PLoS ONE. 2013;8:e58817.

28. Marais E, Mlambo CK, Lewis JJ, et al. Treatment outcomes of multidrugresistant tuberculosis patients in Gauteng. South Africa Infection. 2014;42:405-13.

29. Mishra B, Rockey SM, Gupta S, Srinivasa H, Muralidharan S. Multi-drugresistant tuberculosis: the experience of an urban tertiary care hospital in South India using automated BACTEC 460 TB. Trop Doct. 2012;42:35-7.
30. Chisompola NK, Streicher EM, Muchemwa CMK, Warren RM, Sampson SL. Molecular epidemiology of drug resistant Mycobacterium tuberculosis in Africa: a systematic review. BMC Infect Dis. 2020;20:344.

31. Kigozi G, Heunis C, Chikobvu P, Botha S, van Rensburg D. Factors influencing treatment default among tuberculosis patients in a high burden province of South Africa, International journal of infectious diseases : IJID : official publication of the International Society for. Infect Dis. 2017;54:102.

32. Silva MR, Pereira JC, Costa RR, Dias JA, Guimaraes MDC, Leite ICG. Drug addiction and alcoholism as predictors for tuberculosis treatment default in Brazil: a prospective cohort study. Epidemiol Infect. 2017;145:3516-24.

33. Priedeman Skiles M, Curtis SL, Angeles G, Mullen S, Senik T, Evaluating the impact of social support services on tuberculosis treatment default in Ukraine, PloS One, 13 (2018) e0199513.

34. Lackey B, Seas C, Van der Stuyft P, Otero L. Patient characteristics associated with tuberculosis treatment default: a cohort study in a high-incidence area of lima. Peru PloS ONE. 2015;10:e0128541.

35. Li X, Zhang H, Jiang S, et al. Active pulmonary tuberculosis case detection and treatment among floating population in China: an effective pilot. J Immigr Minor Health. 2010;12:811-5.

36. Li X, Li T, Tan S. Males, ages $>/=45$ years, businessperson, floating population, and rural residents may be considered high-risk groups for tuberculosis infection in Guangzhou, China: a review of 136,394 tb confirmed cases. Rev Inst Med Trop Sao Paulo. 2013;55:366-8.

\section{Publisher's Note}

Springer Nature remains neutral with regard to jurisdictional claims in published maps and institutional affiliations.
Ready to submit your research? Choose BMC and benefit from:

- fast, convenient online submission

- thorough peer review by experienced researchers in your field

- rapid publication on acceptance

- support for research data, including large and complex data types

- gold Open Access which fosters wider collaboration and increased citations

- maximum visibility for your research: over $100 \mathrm{M}$ website views per year

At BMC, research is always in progress.

Learn more biomedcentral.com/submissions 